\title{
POLA PERILAKU PEMBELIAN PRODUK APPAREL UNTUK BALITA OLEH MILLENNIAL MOMS DAN IMPLIKASINYA UNTUK PEMASAR KIDS APPAREL
}

\author{
Annetta Gunawan; Brian Garda Muchardie \\ Management Department, School of Business Management, BINUS University \\ Jln. K.H. Syahdan No.9, Palmerah, Jakarta Barat 11480 \\ annetta_gunawan@hotmail.com; annetta_gunawan@binus.ac.id
}

\begin{abstract}
The phenomenon that recently occurred is the height of the millennial moms busy uploading pictures of their children in such a way they dressed through various social media. Accordingly, the need of the millennial moms in dressing their children up is related to the shopping patterns in kids apparel products. Buying kids products, especially apparel, not only meets the needs, but it is also the pleasure of the millennial mom. The unique characters of the millennial moms' behavior that differ from the mother's of previous generations, make kids apparel marketers need to focus on the overall process of purchasing decisions made by the millennial moms. The purpose of this qualitative study is to explore the patterns of behavior of the millennial moms when shopping apparel products for toddlers, including the factors that influence the need awareness, information search, evaluation of alternatives, purchase behavior, and behavior post-purchase stages. Data collection method used is depth interview since the purpose of this exploratory study is to gain insight and understanding of consumers about a particular topic. The results of this study include an explanation of shopping behavior shown by the millennial moms for kids apparel products in all stages of the purchase decision process, shopping typology of millennial moms in kids apparel products, as well as the implications for marketers.
\end{abstract}

Keywords: shopping behavior, buying decision, millennial mom, kids apparel

\begin{abstract}
ABSTRAK
Fenomena yang akhir-akhir ini terjadi yaitu ramainya para millennial mom yang sibuk meng-upload foto-foto balita mereka yang sedemikian rupa mereka dandani melalui berbagai social media. Sehubungan dengan itu, kebutuhan para millennial mom dalam mendandani anak-anaknya berhubungan dengan pola belanja produk kids apparel. Berbelanja barang-barang anak, khususnya apparel, bukanlah hanya sekedar memenuhi kebutuhan, tapi sekaligus merupakan kesenangan dari millennial mom. Karakter unik millennial mom yang berbeda dengan perilaku ibu pada generasi-generasi sebelumnya membuat pemasar kids apparel perlu fokus pada proses keputusan pembelian yang dilakukan oleh millennial mom secara keseluruhan. Tujuan dari penelitian kualitatif ini adalah untuk menggali pola perilaku para millennial mom ketika berbelanja produkproduk apparel untuk anak mereka pada usia balita, termasuk di dalamnya faktor-faktor yang berpengaruh pada tahap pegenalan kebutuhan, pencarian informasi, evaluasi alternatif, perilaku membeli, dan perilaku pasca-pembelian. Metode pengumpulan data yang digunakan adalah depth interview karena tujuan penelitian eksploratori ini adalah untuk memperoleh insight dan pemahaman konsumen megenai suatu topik. Hasil dari penelitian ini mencakup penjelasan mengenai perilaku belanja yang ditunjukkan para millennial mom untuk produk kids apparel di sepanjang tahap-tahap dalam proses keputusan pembelian, tipologi belanja millennial mom pada produk kids apparel, serta implikasinya untuk pemasar.
\end{abstract}

Kata kunci: pola belanja, keputusan membeli, millennial mom, kids apparel 


\section{PENDAHULUAN}

Selama dua dekade terakhir, Generasi Y atau yang sering disebut dengan millennial, telah menjadi segmen pasar yang penting (Noble et. al, 2009). Saat ini, millennial memiliki $21 \%$ pembelian diskresioner konsumen yang diperkirakan lebih dari 1 triliun dolar dalam daya beli langsung dan berpengaruh besar terhadap generasi yang lebih tua (Butler, 2014). Dalam jangka waktu 10 tahun, $80 \%$ millennial akan memiliki keluarga, dan 83\% 'new moms' sekarang ini telah berada pada kelompok usia tersebut (Butler, 2014). Dengan begitu, bisa dikatakan bahwa kelompok usia ini merupakan segmen berukuran besar dengan daya belanja yang besar pula (BabyCenter $21^{\text {st }}$ Century Mom, 2014).

Karena karakteristik masing-masing generasi berbeda, maka penting bagi pemasar untuk memperlakukan konsumen pada beragam kelompok usia secara berbeda (Rempel, 2009). Misalnya saja, proses pembelian pada baby boomers dimulai dengan kepercayaan yang dimiliki konsumen pada retailer yang memberikan saran untuk memilih produk yang tepat, sedangkan proses pembelian pada millennial diawali dengan pemilihan produk (Parment, 2013).

Millennial mom didefinisikan sebagai ibu yang lahir pada tahun 1978 hingga 1994. Para wanita yang tergolong dalam millennial mom menggunakan social media lebih banyak daripada ibu pada umumnya, dan mereka memanfaatkan teknologi untuk membantu mereka dalam mengelola hidupnya (Goggin et. al, 2014). Sebagai generasi pertama yang bertumbuh dengan adanya Internet dan mobile device, Millennial juga merupakan generasi pertama yang tidak menganggap asing perilaku tweeting dan texting dengan Facebook, Google, Wikipedia, dan YouTube, tapi sebagai aspek normal dari kehidupan sosial mereka dalam mencari informasi (Aquino, 2012). Seperti pernyataan Kotler et. al (2012) berikut ini: "They don't just embrace technology, it's a way of life."

Millennial mom menerapkan cara yang berbeda dengan cara bagaimana mereka dibesarkan, mereka merasa lebih rileks dan bahagia sebagai orang tua dan mereka menghilangkan semua tekanan yang mereka dapatkan saat mereka tumbuh dahulu (BabyCenter $21^{\text {st }}$ Century Mom, 2014). Hal ini berkaitan dengan fenomena yang akhir-akhir ini semakin ramai terjadi. Berbelanja barang-barang anak bukanlah hanya sekedar memenuhi kebutuhan, tapi sekaligus merupakan kesenangan dari millennial mom. Produk apparel anak-anak semakin kreatif dalam hal style dan desain untuk menyediakan alternatif lebih banyak bagi millennial mom untuk 'mendandani' anak-anak mereka, bahkan sudah dimulai ketika sang anak masih berusia balita.

Bahkan, beberapa pihak sampai memberikan gelar anak-anak termodis untuk beberapa anak dari selebritis Hollywood. Salah satunya adalah survei yang dilakukan produsen produk bayi terkemuka di Inggris, My1stYears.com, yang menobatkan di antaranya adalah Suri Cruise (putri dari Katie Holmes), Blue Ivy (putri dari Beyonce), dan Kai Rooney (putri dari Coleen Mary Rooney) sebagai anak-anak termodis, di mana ketiga ibu tersebut merupakan millennial mom (Katie Holmes lahir pada tahun 1978, Beyonce lahir pada tahun 1981, dan Coleen Mary Rooney lahir pada tahun 1986). Di Indonesia pun, para selebritis yang merupakan millennial mom ramai memamerkan anakanak mereka yang mereka dandani mengikuti perkembangan fashion, salah satunya yaitu Almira Tungga Dewi Yudhoyono (putri dari Annisa Pohan yang lahir pada tahun 1981), yang belakangan juga ikut berpartisipasi dalam peragaan busana yang dilakukan ibunya. Fenomena ini juga ditambah dengan ramainya para millennial mom yang sibuk mengunggah foto-foto balita mereka yang sedemikian rupa mereka dandani melalui berbagai social media seperti Facebook, Instagram, dan Path.

Terkait dengan kebutuhan fashion para balita yang tidak menghabiskan dana sedikit ini, Peter et. al (2010) telah menyebutkan bahwa memang anak-anak memiliki pengaruh yang besar terhadap 
keputusan alokasi budget keluarga dan pilihan pembelian yang dilakukan dalam keluarga. Menurut survei yang dilakukan Marketing Charts (2014), millennial mom diidentifikasi 18\% lebih banyak dari ibu lainnya sebagai 'spender' daripada sebagai 'saver'. Hal ini merupakan akibat dari individuindividu yang termasuk kelompok millennial bertumbuh dalam masyarakat kontemporer yang berorientasi pada konsumsi, dan mereka memiliki lebih banyak uang pada masa remajanya daripada generasi sebelumnya (Kennedy, 2001).

Untuk itu, pemasar perlu fokus pada proses keputusan pembelian yang dilakukan oleh millennial mom secara keseluruhan, karena proses pembelian dimulai jauh sebelum pembelian aktual dilakukan dan masih terus berlanjut setelah pembelian aktual dilakukan (Kotler et. al, 2012). Proses kunci di dalam pembuatan keputusan konsumen ialah proses integrasi dengan mana pengetahuan dikombinasikan untuk mengevaluasi dua atau lebih alternatif perilaku, kemudian pilih salah satu, hingga akhirnya hasil dari proses integrasi berupa suatu pilihan yang secara kognitif terwakili sebagai intensi perilaku (Limakrisna dan Supranto, 2007). Tahap-tahap dalam proses keputusan pembelian dimulai dari pengenalan kebutuhan, pencarian informasi, evaluasi alternatif, keputusan untuk membeli, dan perilaku pasca-pembelian (Cant et. al, 2009).

Terdapat keragaman dalam tipologi belanja konsumen, sebagaimana disebutkan oleh Butler (2014) bahwa millennial bukan merupakan kelompok homogen. Konsumen cenderung untuk menunjukkan orientasi belanja yang berbeda, berdasarkan kepribadian dan karakteristik individualnya (Bae, 2004). Mafini et. al (2014) membagi tipologi belanja konsumen millennial pada produk apparel menjadi 7 kelompok, seperti dipaparkan pada tabel berikut ini:

Tabel 1 Tipologi konsumen millennial pada produk apparel

\begin{tabular}{ll}
\hline Factors label & Factor description \\
\hline $\begin{array}{l}\text { Fashion conscious } \\
\text { Hedonistic }\end{array}$ & $\begin{array}{l}\text { A characteristic representing a consumer who is motivated to keep up to date with styles and fashion trends. } \\
\text { Brand conscious }\end{array}$ \\
$\begin{array}{l}\text { A characteristic measuring the degree to which a consumer finds shopping activity enjoyable and shops for the fun of it. } \\
\text { Measuring a consumer's orientation to buying the more expensive, well-known brands. }\end{array}$ \\
$\begin{array}{l}\text { A characteristic identifying consumers who appear to like new and innovative products and gain excitement from seeking } \\
\text { new products. }\end{array}$ \\
$\begin{array}{l}\text { A characteristic measuring the degree to which a consumer searches carefully and systematically for the best quality in } \\
\text { products. }\end{array}$ \\
$\begin{array}{l}\text { A characteristic identifying those consumers who perceive too many brands and stores from which to choose, } \\
\text { experiencing information overload in the market. } \\
\text { A characteristic indicating consumers who have favourite brands and stores, who have formed habits around these. }\end{array}$ \\
\hline
\end{tabular}

Sumber: Mafini et. al (2014)

Salah satu perilaku belanja unik dari kelompok millennial mom yaitu mereka lebih memilih untuk membeli produk-produk apparel di toko, tapi dengan mencari informasi sebelumnya terlebih dahulu mengenai produk yang akan dibeli. Sebuah studi yang dilakukan Forest City and Alexander Babbage mengungkapkan bahwa $71 \%$ pengeluaran bulanan dari kelompok millennial dibuat secara fisik di toko, dan $60 \%$ dari waktu belanja mereka dihabiskan untuk mencari tahu tentang produk yang akan dibeli terlebih dahulu sebelum mengunjungi toko untuk berinteraksi secara langsung dengan produk tersebut (Loboda, 2014). Menurut pernyataan dari Solis (2011) bahwa millennial moms mencari informasi sebanyak 9,2 kali per bulan ketika akan membeli produk.

Sehubungan dengan hal tersebut, Bazaarvoice mengungkapkan bahwa $51 \%$ millennial mengatakan bahwa opini konsumen yang ditemukan pada website perusahaan memiliki dampak yang lebih besar pada keputusan pembelian mereka daripada rekomendasi dari teman dan keluarga. Menganalisa informasi tentang perusahaan yang berasal dari crowd sudah dimulai dan akan terus 
menjadi sumber yang dipandang terpercaya daripada sekedar mendengarkan feedback mengenai perusahaan tersebut dari lingkungan sosial (Honigman, 2013). Meskipun begitu, Weber Shandwick (2014) membuktikan bahwa 9 dari 10 millennial mom saling berbagi informasi mengenai produkproduk apparel, retail store, dan bahan makanan. Millennial mom lebih terhubung secara digital dan secara aktif mencari informasi dan saran, mereka lebih cenderung untuk repin, repost, retweet, dan berbagi informasi dengan yang lain, terutama teman dan ibu lainnya (DeLong, 2013).

Berdasarkan uraian fenomena di atas dan masih minimnya penelitian di pasar Indonesia mengenai perilaku belanja millennial mom pada produk apparel anak-anak, penulis tertarik untuk melakukan penelitian kualitatif dengan tujuan menggali pola perilaku para millennial mom ketika berbelanja produk-produk apparel untuk anak mereka pada usia balita, termasuk faktor-faktor yang berpengaruh pada tahap pegenalan kebutuhan, pencarian informasi, evaluasi alternatif, perilaku membeli, dan perilaku pasca-pembelian. Sehingga akan diperoleh suatu gambaran mengenai perilaku konsumen millennial mom bagi para pembaca, dan hasil penelitian ini diharapkan juga dapat bermanfaat bagi para pemasar di industri apparel anak-anak, khususnya balita, untuk mengetahui karakteristik target pasar utamanya, dan pada akhirnya dapat memberikan insight serta pertimbangan bagi pengambilan keputusan pemasaran oleh pemasar di industri apparel anak-anak. Selain itu, hasil dari penelitian ini juga diharapkan dapat memberikan kontribusi bagi perkembangan riset pemasaran, baik profesional maupun akademik, khususnya dalam bidang perilaku konsumen.

\section{METODE}

Penelitian ini merupakan penelitian eksploratori yang dilakukan secara kualitatif, di mana penelitian ini bertujuan untuk memperoleh pemahaman tentang alasan-alasan dan motivasi yang mendasari perilaku konsumen (Malhotra, 2012). Metode pengumpulan data yang digunakan adalah depth interview karena tujuan penelitian eksploratori ini adalah untuk memperoleh insight dan pemahaman konsumen megenai suatu topik.

Teknik pengambilan sampel yang digunakan yaitu convenience sampling yang merupakan salah satu metode non-probability sampling, dengan jumlah sampel sebanyak 15 orang millennial moms. Hal ini berdasarkan pernyataan Malhotra (2012) bahwa jumlah sampel dalam penelitian kualitatif berukuran kecil dari kasus yang tidak representatif. Kriteria responden yang menjadi target peneliti yaitu ibu muda yang tergolong dalam generasi millennial (berusia 20-36 tahun) dan memiliki anak (laki-laki maupun perempuan) yang berusia 5 tahun ke bawah.

Depth interview dilakukan secara semi-terstruktur dengan kerangka dimensi keputusan pembelian yang terdiri dari tahap pengenalan kebutuhan, pencarian informasi, evaluasi alternatif, keputusan untuk membeli, dan perilaku pasca-pembelian. Berdasarkan kerangka tersebut, panduan outline topik-topik depth interview yang ditanyakan sebagai berikut: (1) Faktor-faktor apa saja yang mempengaruhi millennial mom dalam menyadari kebutuhan akan produk apparel untuk anak mereka dan seberapa penting kebutuhan akan produk apparel untuk anak bagi millennial mom? (2) Sumbersumber mana saja yang dijadikan referensi dalam tahap pencarian informasi sebelum membeli produk dan seberapa signifikan kontribusi dari sumber-sumber tersebut dalam keputusan pembelian? (3) Faktor-faktor apa saja yang dipertimbangkan dan atau mempengaruhi tahap evaluasi alternatif produk apparel untuk anak yang akan dibeli oleh millennial mom? (4) Bagaimana pola perilaku millennial mom ketika melakukan tindakan pembelian produk apparel untuk anak mereka? Adakah pengaruh situasional yang berkontribusi terhadap tindakan pembelian yang dilakukan? (5) Bagaimana perilaku pasca-pembelian yang ditunjukkan oleh millennial mom dalam konteks produk kids apparel? 


\section{HASIL DAN PEMBAHASAN}

\section{Pengenalan Kebutuhan}

Kebutuhan produk apparel untuk anak balita, dianggap oleh millennial mom sebagai kebutuhan yang termasuk krusial, dan merupakan kebutuhan utama pada kelompok umur tersebut setelah kebutuhan akan makanan dan gizi. Namun, bagi millennial mom yang memiliki anak usia di bawah 1 tahun, kebutuhan apparel masih berada di urutan ke-sekian setelah susu dan produk perlengkapan bayi lainnya, seperti pompa ASI, popok bayi, dan tisu basah.

Untuk anak berusia di bawah 1 tahun, millennial mom membeli sekaligus banyak dan meyimpan persediaan baju, kaos kaki, dan sepatu, karena ukuran tubuh bayi yang cepat berubah. Sedangkan, untuk millennial mom dengan anak balita usia di atas 1 tahun, pembelian produk apparel sangat jarang dilakukan secara terencana, hampir semua responden menyatakan bahwa mereka baru membeli saat sedang jalan-jalan dan tertarik pada produk tertentu (impulse buying). Hal ini berlaku pula untuk baju untuk moment khusus seperti menghadiri pesta pernikahan, biasanya millennial mom membeli baju yang mereka suka walaupun ukurannya masih terlalu besar, sehingga dapat disimpan untuk keperluan mendatang. Dengan kata lain, kebutuhan timbul bukan lagi karena baju atau sepatu sudah kekecilan, atau sudah sampai bosan dipakai, karena pembelian sering dilakukan dan barang disimpan untuk dipakai ketika butuh. Pembelian produk apparel ini rata-rata dilakukan antara 1 sampai 2 bulan sekali, dan dalam sekali pembelian biasanya lebih dari 1 buah.

Hal tersebut sejalan dengan hasil survei yang telah dilakukan sebelumnya oleh TIME (Honigman, 2013), yaitu:

" $52 \%$ of millennials were more likely to make impulse purchases than any other generation. There could be correlations drawn to how fast our culture of consumption is moving as compared to past generations, which could affect how quickly millennials make a decision to buy when shopping."

Pada beberapa anak laki-laki, kebutuhan juga timbul dari keinginan sang anak untuk memakai kostum atau baju bergambar superhero, mengikuti tren film yang sedang marak pada saat-saat tertentu. Namun hal ini berlaku bagi millennial mom yang kurang mengutamakan faktor style, sedangkan millennial mom yang suka mengikuti tren fashion anak-anak, walaupun anaknya laki-laki tapi mereka tetap mengutamakan style daripada gambar-gambar seperti itu.

Implikasinya bagi para pemasar produk kids apparel adalah bahwa kebutuhan untuk para balita ini lebih mudah untuk 'diciptakan', karena kuncinya ada di kecenderungan millennial mom untuk melakukan impulse buying pada kelompok produk ini. Penataan baju, sepatu, dan aksesoris lainnya pada mannequin akan menjadi magnet yang cukup kuat untuk menarik millennial mom setidaknya masuk ke dalam toko terlebih dahulu. Dan yang perlu dicatat, penataan mannequin ini sebaiknya diganti secara berkala dalam jangka waktu yang tidak terlalu lama, melihat perilaku mereka yang sering berjalan-jalan di mall dan mencari apakah ada yang baru.

\section{Pencarian Informasi}

Pada tahap pencarian informasi, millennial mom biasa meminta referensi dari dari ibu, teman, atau saudara, untuk bertanya-tanya mengenai produk kids apparel. Namun referensi tersebut tidak terlalu berpengaruh, sifatnya hanya sekedar menambah informasi. Diakui oleh beberapa responden bahwa, referensi dari orang lain akan lebih signifikan untuk produk-produk peralatan anak lainnya yang sifatnya lebih jangka panjang dan berhubungan dengan kesehatan, seperti peralatan makan dan minum. 
Beberapa millennial mom, yang waktunya banyak terserap oleh pekerjaan di kantor, tidak memiliki cukup waktu untuk browsing informasi mengenai produk kids apparel, sehingga proses pencarian informasi baru dilakukan secara singkat sambil berjalan-jalan di mall, ditambah dengan masukan dari teman atau keluarga. Namun, millennial mom yang memiliki waktu luang lebih banyak, seperti ibu rumah tangga atau sudah memiliki posisi manajerial di kantornya, umumnya akan browsing produk-produk kids apparel melalui Internet, terutama di online shop. Bahkan, millennial mom yang suka melakukan pencarian informasi di Internet ini lebih sering mengandalkan informasi yang mereka dapatkan melalui media tersebut daripada meminta referensi dari teman atau keluarga.

Millennial mom suka mencari model baju yang sedang tren untuk anak-anak mereka, seperti yang dinyatakan oleh salah 1 responden berikut ini: "Ibu jaman sekarang beda dengan jaman dulu, kalau jaman dulu membelikan baju untuk anak asal yang lucu saja, tapi sekarang kalau ibunya keren, anaknya juga harus keren, makanya ibunya akan berusaha mendandani anak lebih daripada jaman dulu". Pencarian informasi mengenai model baju untuk anak ini dilakukan dengan mengunjungi situssitus online shop, melihat-lihat toko di mall, hingga memperhatikan apa yang dipakai oleh artis Korea di drama. "Kalau lihat drama Korea, bajunya lucu-lucu, jadi ingin mendandani anakku seperti itu," papar salah seorang responden. Beberapa millennial mom juga mengaku sengaja berburu model baju yang menarik di mall-mall, untuk menunggu sampai model tersebut mendapat diskon sehingga bisa membeli dengan harga yang lebih murah.

Seperti pendapat Aquino (2012) berikut: "With this generation, everything has to be visual and contextual. Gen Y processes information on an intuitive level. They will form impressions about a product based on how it looks and what it does, not what advertisers say about it." Implikasinya untuk para pemasar produk kids apparel adalah dengan menyediakan informasi bagi para millennial mom melalui Internet, misalnya dengan menyertakan contoh artis atau model yang sedang bergaya menggunakan padu padan baju, sepatu, dan aksesoris produknya, juga dilengkapi dengan pendapat atau comment positif dari konsumen lainnya yang telah lebih dulu melakukan pembelian.

\section{Evaluasi Alternatif}

Fort Mill Times menyatakan bahwa: "Millennial parents buy significantly more based on price than they do on quality. Before being parents, millennial buying decisions were $57 \%$ on quality, with children it drops to 50\%. Many millennials prefer to save money after having children, which is expected with the addition of a new expenses for the family," (Honigman, 2013). Hal tersebut sejalan dengan apa yang ditemukan oleh peneliti bahwa harga merupakan faktor utama yang menjadi pertimbangan millennial mom dalam mengevaluasi alternative pada kelompok produk kids apparel. Kebanyakan responden spontan menjawab "sering sale", "murah", atau "harganya make sense" ketika ditanya mengenai alasan mereka menyukai toko yang biasa mereka datangi untuk berbelanja produk kids apparel. Walaupun karakter millennial mom mudah terprovokasi untuk melakukan impulse buying, namun generasi ini masih memiliki pertimbangan rasional yang cukup mengenai budget yang mereka miliki untuk dialokasikan pada kebutuhan apparel anak-anak. Walaupun ukuran murah atau tidaknya barang tergantung lagi kepada tingkat penghasilan masing-masing, namun secara umum mereka mengutamakan harga yang sesuai dengan kualitas yang ditawarkan. Itulah definisi 'murah' menurut mereka.

Faktor lain yang menjadi bahan evaluasi bagi para millennial mom adalah tersedianya banyak variasi model dan warna produk yang ditawarkan. Seperti hasil survei dari Accenture berikut ini:

"Of survey respondents, 92\% said that real-time product availability would influence where they shop. This is a statistic that brands should not ignore, since providing customers with the availability of product online or in stores is possible, which according to this survey, is an important factor that influences Gen Y shopping behavior, (Honigman, 2013). 
Hal ini berkaitan dengan karakter millennial mom yang mencari variasi model fashion yang sedang tren untuk anak-anak mereka.

Faktor penting lainnya yang tidak terlupakan adalah kualitas dan bahan dari produk yang ditawarkan. Walaupun millennial mom mementingkan model baju yang akan dipakai anaknya, namun faktor kualitas menjadi pengimbangnya. Seperti pendapat salah satu responden berikut ini: “... lebih mengutamakan kenyamanan sang anak, sehingga anak lebih gampang bergerak pada usia balita, kalau model baju yang berenda menyebabkan iritasi." Ditambahkan oleh responden lainnya bahwa, "Anakanak sekarang lebih gampang iritasi kulitnya, jadi ibu harus selektif memilih bahan pakaian untuk anak."

Untuk produk sepatu anak, kebanyakan millennial mom lebih brand-minded daripada untuk produk pakaian, karena berkaitan dengan perkembangan tulang sang anak. Sehingga faktor kesehatan menjadi pertimbangan utama dalam memilih sepatu untuk sang anak. Di samping itu, kembali lagi pada faktor kualitas, di mana millennial mom lebih memilih sepatu yang selain sehat, juga tahan lama.

Implikasinya bagi para pemasar, sebaiknya menawarkan harga yang dipersepsikan oleh konsumen sesuai dengan kualitas, serta sering mengadakan diskon untuk produk yang berbeda-beda, walaupun bukan diskon besar-besaran, karena diskon tetap merupakan daya tarik utama bagi para millennial mom. Selain itu, ragam produk yang di-display di toko harus sering berganti-ganti dan disajikan secara lengkap. Yang perlu diingat pula adalah bagaimana mengelola persediaan barang dalam berbagai ukuran, karena rentang usia balita sangat rentan dengan perbedaan ukuran. Lebih baik menyimpan persediaan ukuran yang lebih besar, karena millennial mom cenderung bersedia membeli baju dengan ukuran lebih besar agar bisa disimpan untuk dipakai kemudian, yang penting model dan bahannya cocok untuk anak mereka.

\section{SIMPULAN}

\section{Keputusan untuk Membeli}

Rata-rata millennial mom setuju bahwa mereka tidak memiliki hanya satu toko langganan untuk membeli produk kids apparel, melainkan ada beberapa toko tertentu yang biasa mereka kunjungi untuk melihat-lihat apakah ada model terbaru atau yang bagus, setelah itu mereka akan memutuskan untuk membeli. Namun, untuk produk sepatu anak, millennial mom cenderung lebih loyal pada merek tertentu. Ada juga beberapa millennial mom yang biasa membeli melalui personal selling, di mana teman-teman kantor mereka yang menjual.

Ketika melakukan pembelian, hampir semua millennial mom mengaku bahwa mereka hampir selalu ditemani suami. Selain itu, suami juga memberikan kontribusi yang cukup signifikan dalam keputusan pembelian. Mengingat kecenderungan millennial mom yang mudah terpengaruh hingga melakukan impulse buying, biasanya suami adalah pihak yang berperan sebagai 'rem' untuk menahan pembelian yang dirasa belum perlu. Millennial mom juga bertanya mengenai pendapat suami mereka tentang produk kids apparel yang akan dibeli, apakah bagus atau tidak, dan apakah matching dengan anaknya atau tidak.

Selain suami, ternyata sang anak juga merupakan salah satu penyumbang suara bagi keputusan pembelian yang dilakukan millennial mom. Satu hal yang berlaku bagi semua responden adalah bahwa sang anak nantinya bersedia memakai baju, sepatu, atau aksesoris yang telah mereka beli. Sehingga, untuk menghindari pembelian yang telah dilakukan sia-sia, maka beberapa millennial mom akan melakukan pembelian ketika mereka mengajak serta sang anak, untuk memastikan apakah anaknya mau memakai nanti. Tapi keputusan utama tetap di tangan millennial mom. Seperti 
pengakuan dari responden berikut yang mewakili suara lainnya: "Kalau anaknya masih bisa dibujuk, biasanya tetap mengikuti kemauan ibunya, tapi kalau sang anak sudah sampai nangis, maka akhirnya kemauan sang anak yang akan diikuti." Selain itu, beberapa millennial mom juga melakukan pembelian karena memenuhi permintaan sang anak, biasanya menyangkut gambar kartun di baju, atau warna baju, atau model sepatu yang ingin dimiliki oleh sang anak.

Implikasinya bagi para pemasar kids apparel adalah pengaruh situasional juga merupakan salah satu faktor yang harus diperhatikan. Pengaruh suami dan sang anak bagi millennial mom dalam melakukan keputusan pembelian, membuat pemasar harus menyasar aktivitas marketing bukan saja terhadap sang ibu. Kondisi mood anak bisa dipengaruhi agar ketika di toko, mereka setuju dengan pilihan sang ibu, atau bahkan me-request pembelian. Misalnya, toko dirancang bukan hanya sebagai tempat belanja bagi sang ibu, tapi juga menarik bagi sang anak, dengan menyediakan mainan atau fasilitas lainnya yang membuat anak tertarik untuk 'ikut berbelanja'.

\section{Perilaku Pasca Pembelian}

Perilaku pasca pembelian para millennial mom pada kelompok produk kids apparel hampir sama pada umumnya. Kekecewaan terhadap produk yang dibeli mengakibatkan mereka tidak kembali pada penjual tersebut. Mengenai produk yang tidak sesuai ekspektasi, para responden mengaku hampir tidak pernah kecewa dengan produk kids apparel yang mereka beli di toko fisik. Namun sebaliknya, online shop mendapatkan komentar negatif dari hampir seluruh responden, dengan kasus pada umumnya bahwa bahan dari pakaian yang dibeli ternyata tidak sesuai dengan perkiraan mereka, seperti luntur saat dicuci atau membuat kulit anak iritasi. Akibatnya, mereka menjadi berpikir ulang untuk melakukan pembelian online lagi. Pembelian online kebanyakan dilakukan untuk produk apparel selain pakaian, yaitu sepatu dan aksesoris anak. Untuk pakaian, millennial mom lebih banyak membeli di toko secara fisik.

Bila millennial mom puas dengan produk yang dibeli, mereka akan melakukan re-purchase pada kali berikutnya dan memberikan rekomendasi pada sesame konsumen. Namun, rekomendasi dari para millennial mom ini bergantung dari karakter masing-masing, di mana millennial mom yang cenderung tomboy tidak terlalu aktif membagikan pengalamannya, hanya bila ditanya oleh sesamanya baru mereka bercerita. Sedangkan, millennial mom yang cenderung fashionista atau feminim, lebih aktif untuk men-share kepuasan mereka terhadap produk atau toko di mana mereka membeli. Namun rekomendasi untuk produk perlengkapan anak lainnya yang berhubungan dengan kesehatan atau makanan anak, diakui oleh para millennial mom lebih sering mereka lakukan daripada produk kids apparel, dengan alasan bahwa selera penampilan orang berbeda-beda.

Implikasinya bagi para pemasar adalah, mengingat kecenderungan millennial mom yang sebenarnya memungkinkan pemasar mengandalkan word of mouth namun merasakan bahwa pengalaman pada kelompok produk kids apparel tidak terlalu tepat untuk di-share, pemasar dapat memberikan stimulus sehingga tercipta word of mouth yang lebih aktif. Misalnya dengan mengadakan campaign untuk menciptakan viral marketing, atau kontes yang memberikan reward bagi para millennial mom yang melakukan share terbaik dan terbanyak mengenai produk mereka.

Sementara itu, untuk mengatasi kekecewaan yang kebanyakan dialami oleh millennial mom saat membeli secara online, pemasar sebaiknya memberikan garansi dan rasa aman, misalnya dengan menyediakan kolom 'review' yang akan diisi oleh konsumen lainnya, di samping tentu saja dengan tetap memperhatikan kualitas produk yang ditawarkan. 


\section{Tipologi Millennial Mom untuk Produk Kids Apparel}

Tipologi konsumen millennial pada produk apparel yang dikemukakan Mafini (2014) ternyata juga dapat diimplikasikan pada produk kids apparel, seperti penjelasan berikut ini:

\section{Hedonistic}

Hasil survei yang dilakukan oleh Marketing Charts (2014) menyatakan bahwa:

"Millennial mothers present a particularly attractive target for brands for two other distinct reasons: they're 18\% more likely than the average mother to identify as a "spender" rather than a "saver;" and they're also 18\% more likely to agree that brand name is the best indication of quality."

Seperti yang telah diuraikan di atas, bahwa millennial mom memiliki kecenderungan untuk melakukan impulse buying, sehingga mereka cenderung menghabiskan banyak alokasi budget untuk produk kids apparel. Seperti pengakuan dari beberapa responden: “... lebih mementingkan anak daripada penampilan sendiri...", "Kalau sudah punya anak, semuanya buat anak, padahal buat diri sendiri iritirit ...", "Tidak tahu mengapa, saya suka mendandani anak, padahal saya sendiri bukan termasuk yang modis untuk diri sendiri ...". Ternyata millennial mom juga bersifat 'hedon' dalam hal kebutuhan apparel anak mereka. Tipe ini berkaitan erat dengan impulse buying yang dilakukan oleh para millennial mom. "Fashion involvement and positive emotion had positive effects on consumers' fashion-oriented impulse buying behavior, while hedonic consumption tendency was an important mediator in determining fashion-oriented impulse buying," (Park et.al, 2006).

\section{Brand Conscious dan Quality Conscious}

Sesuai hasil pengumpulan data dari peneliti, tipe yang berorientasi pada brand ini lebih berlaku untuk produk sepatu, sedangkan untuk pakaian dan aksesoris, millennial mom lebih berorientasi pada fashion conscious. Hal ini juga dikarenakan oleh umur produk dari sepatu yang cenderung lebih panjang daripada produk apparel lainnya, dan berhubungan dengan pertumbuhan tulang anak. Sedangkan kualitas tetap menjadi faktor utama yang dipertimbangkan ketika akan membeli semua jenis produk kids apparel, terlepas dari faktor style yang juga memberikan kontribusi pada keputusan pembelian millennial mom.

\section{Novelty seeking dan fashion conscious}

Dalam Honingman (2013), Weber Shandwick menyatakan bahwa: "Millennial moms spend 4 hours more per week than the average mom spends on social networks. They spend an average of 17.4 hours per week on their social media networks." Hal ini berkorelasi dengan kebiasaan para millennial mom yang senang mem-posting foto anak-anak mereka yang sedang bergaya bak fashionista. Beberapa responden juga menyatakan bahwa sang anak sendiri suka difoto dan sang anak mengirimkan foto diri yang sedang bergaya ke ayah mereka melalui media elektronik. Lainnya mengakui bahwa mereka suka 'memamerkan' anak mereka di depan umum saat pesta atau moment lain, agar dipuji oleh orang. Motivasi inilah yang mendasari perilaku belanja millennial mom yang mencari keragaman saat memilih produk dan berorientasi pada fashion yang sedang tren bagi anak. 


\section{DAFTAR PUSTAKA}

Aquino, J. (2012). Gen Y: The Next Generation of Spenders. Diakses dari http://www.destinationcrm.com/Articles/Editorial/Magazine-Features/Gen-Y-The-NextGeneration-of-Spenders-79884.aspx.

Baby Center Solution (2014). Millennial Mom Report Highlights. BabyCenter $21^{\text {st }}$ Century Mom ${ }^{\circledR}$ Insights Series, diakses dari http://www.babycentersolutions.com/docs/BabyCenter_2014_Millennial_Mom_Report.pdf.

Bae, S. (2004). Shopping Pattern Differences of Physically Active Korean and American University Consumers for Athletic Apparel. Doctoral Thesis, College of Education, Florida State University.

Butler, C. (2014). Babes with Babies: How Millennial Moms Shop Part 1. Diakses dari http://millennialmarketing.com/2014/06/babes-with-babies-how-millennial-moms-shop-part$1-2 /$.

Cant, M. C., Strydom, J. W., Jooste, C. J., du Plessis. P. J. (2009). Marketing Management. Juta and Company Ltd.

DeLong, M. (2013). Marketing to Millennial Moms. Core Commerce. Diakses dari https://www.corecommerce.com/blog/marketing-to-millennial-moms.

Goggin, Gerard \& Hjorth, L. (2014). Routledge Companion to Mobile Media. Routledge.

Honigman, B. (2013). How Millennials are Shopping: 20 Interesting Statistics \& Figures. Diakses dari https://medium.com/@brianhonigman/how-millennials-are-shopping-20-interestingstatistics-figures-c76fb1231fbb.

Kennedy, L. (2001). The Up and Coming Generation. Retail Merchandising, 41(8), 66-73.

Kotler, Philip \& Armstrong, G. (2012). Principles of Marketing, $14^{\text {th }}$ edition. Pearson Education Limited.

Limakrisna, N., Supranto, J. (2007). Perilaku Konsumen dan Strategi Pemasaran. Mitra Wacana Media.

Loboda, A. (2014). The Millennial Mom. Kendal King Group. Diakses dari http://kendalkinggroup.com/kkg-velocity-blog/millennial-mom/.

Mafini, C., Dhurup, M. \& Mandhlazi, L. (2014). Shopper Typologies amongst A Generation Y Consumer Cohort and Variations in Terms of Age in The Fashion Apparel Market. Acta Commercii, 14(1), Art.

Marketing Charts. (2014). Millennial Moms' Shopping Attitudes. Marketing Charts, diakses dari http://www.marketingcharts.com/online/millennial-moms-shopping-attitudes-39550/.

Malhotra, N. K. (2012). Basic Marketing Research: Integration of Social Media, $4^{\text {th }}$ edition. Pearson Education. 
Noble, S. M., Haytko, D. L. \& Phillips, J. (2009). What Drives College-Age Generation Y Consumers. Journal of Business Research, 62, 617-628.

Park, E. J., Eun Y. K., Forney, J. C. (2006). A Structural Model of Fashion-oriented Impulse Buying Behavior. Journal of Fashion Marketing and Management: An International Journal, 10 (4), 433-446.

Parment, A. (2013). Generation Y vs. Baby Boomers: Shopping Behavior, Buyer Involvement and Implications for Retailing. Journal of Retailing and Consumer Services, 20(2), 189-189.

Peter, J. P. Olson, J. C. (2010). Consumer Behavior \& Marketing Strategy, $9^{\text {th }}$ edition. McGraw Hill.

Rempel, C. (2009). Marketing to Different Generations. Security Dealer \& Integrator 31(2), 3436.

Solis, B. (2011). The End of Business As Usual. John Wiley \& Sons.

Weber Shandwick. (2014). Digital Women Influencers: Millennial Moms. KRC Research, diakses dari http://www.webershandwick.com/uploads/news/files/MillennialMoms ExecSummary.pdf. 